\title{
Properties of Si:V Annealed under Enhanced Hydrostatic Pressure
}

 \\ L. $\mathrm{CHOW}^{e}, \mathrm{R}$. VANFleEt ${ }^{f}$ AND M. PRUJSZCZYK ${ }^{a}$ \\ ${ }^{a}$ Institute of Electron Technology, al. Lotników 32/46, 02-668 Warsaw, Poland \\ ${ }^{b}$ Institute of Electronic Materials Technology, 01-919 Warsaw, Poland \\ ${ }^{c}$ Institute of Atomic Energy POLATOM, 05-400 Otwock-Świerk, Poland \\ ${ }^{d}$ Institute of Physics, PAS, al. Lotników 32/46, 02-668 Warsaw, Poland \\ ${ }^{e}$ University of Central Florida, Orlando, FL 32816, USA \\ ${ }^{f}$ Department of Physics, Brigham Young University, Provo, Utah, 84604, USA
}

\begin{abstract}
It is known that processing of silicon implanted with vanadium, $\mathrm{Si}: \mathrm{V}$, at high temperature-pressure, HT-HP, can lead to magnetic ordering within the V-enriched area. New data concerning structure of Si:V (prepared using $\mathrm{V}^{+}$doses, $D=(1-5) \times 10^{15} \mathrm{~cm}^{-2}$, and energy, $\left.E=200 \mathrm{keV}\right)$, as implanted and processed for up to $10 \mathrm{~h}$ at $\mathrm{HT} \leq 1400 \mathrm{~K}$ under enhanced hydrostatic pressure, $\mathrm{HP} \leq 1.1 \mathrm{GPa}$, are presented. In effect of implantation, amorphous $(\mathrm{a}-\mathrm{Si})$ area is produced near range of implanted species. Transmission electron microscopy, secondary ion mass spectrometry, X-ray, and synchrotron methods were used for sample characterisation. At HT-HP the a-Si layer is subjected to solid phase epitaxial re-growth. Depending on HP, distinct solid phase epitaxial re-growth and formation of $\mathrm{VSi}_{2}$ are observed at $\mathrm{HT} \geq 720 \mathrm{~K}$. HP applied at processing results in the improved solid phase epitaxial re-growth in $\mathrm{Si}: \mathrm{V}$. This can be related, among others, to the effect of $\mathrm{HP}$ on diffusivity of $\mathrm{V}^{+}$ and of implantation-induced point defects. Our results can be useful for development of the new family of diluted magnetic semiconductors.
\end{abstract}

PACS: 61.72.Dd, 61.72.uf, 64.75.Qr, 66.30.Xj, 81.40.Xj

\section{Introduction}

Implantation of silicon with some transition metals (TM), vanadium among them, and subsequent processing of resulting Si:TM at high temperature (HT) under enhanced hydrostatic pressure (HP) can lead to magnetic ordering within the buried TM-enriched area. In particular, magnetic ordering has been reported, also by us, for the HT-HP treated Si:Mn, Si:Cr, Si:V and similar structures [1-5]. This new class of diluted magnetic semiconductors (DMS) is now intensively investigated, also because the Curie temperature of some materials seems to reach the room temperature level.

It is interesting to note that, when considering the data concerning magnetic and other properties of $\mathrm{Si}: \mathrm{V}$, one needs to account for an existence of so-called quasi-ferromagnetism, observed e.g. in Si:He, and earlier suggested by Figielski [6].

As it was reported earlier [3], HP applied at processing results in the changed crystallographic perfection of Si:V. This has been suggested to be caused, among others, by

\footnotetext{
* corresponding author; e-mail: misiuk@ite.waw.pl
}

the effect of HP on diffusivity of $\mathrm{V}^{+}$and of implantation-induced point defects.

New data concerning structure and related properties of $\mathrm{Si}: \mathrm{V}$, as implanted and processed for up to $5 \mathrm{~h}$ at $\mathrm{HT} \leq 1400 \mathrm{~K}$ under $\mathrm{HP} \leq 1.2 \mathrm{GPa}$, are now presented.

Our report contributes to understanding of the compositional and structural properties of single crystalline silicon implanted with medium dosage of vanadium ions and processed at HT-HP.

\section{Experimental}

$\mathrm{Si}: \mathrm{V}$ (implanted fluences $D_{\mathrm{V}+}=(1-5) \times 10^{15} \mathrm{~cm}^{-2}$, implantation energy $E_{\mathrm{V}+}=200 \mathrm{keV}$, projected range of $\mathrm{V}^{+}, R_{\mathrm{p}}=170 \mathrm{~nm}$ ) was prepared by implantation, at $T \leq 350 \mathrm{~K}$, of ${ }^{51} \mathrm{~V}^{+}$into (001) oriented Czochralski grown silicon $(\mathrm{Cz}-\mathrm{Si})$, containing oxygen interstitials with the concentration, $c_{0}=9 \times 10^{17} \mathrm{~cm}^{-3}$.

The $\mathrm{Si}: \mathrm{V}$ samples were processed for up to $5 \mathrm{~h}$ at $\mathrm{HT} \leq$ $1400 \mathrm{~K}$ under either $10^{5} \mathrm{~Pa}$ or $\mathrm{HP} \leq 1.1 \mathrm{GPa}$, exerted by chemically inert Ar atmosphere.

The as implanted and HT-HP processed samples were investigated by transmission electron microscopy (TEM), secondary mass spectrometry (SIMS, Cameca 
5 F), X-ray, and synchrotron methods (at the F1 and F2 experimental stations of the DORIS III synchrotron in HASYLAB, DESY).

\section{Results and discussion}

It is known that the amorphous (a-Si) area is produced in Si:V $\left(D>1 \times 10^{15} \mathrm{~cm}^{-2}\right)$ near $R_{\mathrm{p}}$ under implantation conditions used in our research (with introduced energy exceeding the amorphization threshold). As seen in the $\mathrm{V}$ depth profiles obtained by SIMS (Fig. 1), maximum V concentration in as implanted $\mathrm{Si}: \mathrm{V}\left(D=1 \times 10^{15} \mathrm{~cm}^{-2}\right)$ reaches the level of about 0.1 at.\% while any irregularities are detected in the mentioned profile.



Fig. 1. Depth profiles of vanadium in $\mathrm{Cz}-\mathrm{Si}: \mathrm{V}(D=$ $1 \times 10^{15} \mathrm{~cm}^{-2}$ ), as implanted and processed for $10 \mathrm{~h}$ at $723 \mathrm{~K}$ under $10^{5} \mathrm{~Pa}$ and $1.1 \mathrm{GPa}$ and for $5 \mathrm{~h}$ at $1400 \mathrm{~K}$ under $0.3 \mathrm{GPa}$.
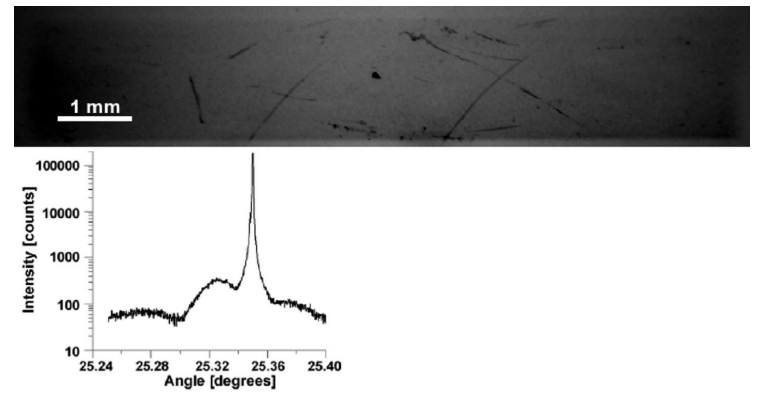

Fig. 2. Synchrotron monochromatic beam topograph $(\lambda=0.1115 \mathrm{~nm})$ and $004 \mathrm{RC}$, from as implanted $\mathrm{Si}: \mathrm{V}$ $\left(D=5 \times 10^{15} \mathrm{~cm}^{-2}\right)$.

As follows from the shape of rocking curve (additional maxima, Fig. 2), as implanted $\mathrm{Si}: \mathrm{V}$ presents the layered structure. The topograph reveals only some relatively strong contrasts, which may be caused by implantation. The amorphous, a-Si zone, is formed near $R_{\mathrm{p}}$. At annealing, under atmospheric pressure as well as under HP, the
a-Si layer is subjected to solid phase epitaxial re-growth (SPER).

Even processing of $\mathrm{Si}: \mathrm{V}$ at so low temperature as $723 \mathrm{~K}$ results in clearly detectable changes of the depth profiles. The $\mathrm{V}$ concentration peaks near $R_{\mathrm{p}}$ and reaches the level of about 0.6 at.\%. Simultaneously, the V concentration decreases markedly at a little deeper position (Fig. 1).

SPER at $723 \mathrm{~K}$ results in slight shift of the a (amorphous) $-c$ (crystalline) interface toward the Si surface. Since the solubility of $\mathrm{V}$ in crystalline $\mathrm{Si}$ is very low [7], the $\mathrm{V}$ ions are expelled from the re-growth region at re-crystallization, as the $\mathrm{a}-\mathrm{c}$ interface moves toward the surface. Through this "snow-plow" process, a minimum in the $\mathrm{V}$ concentration profile is formed around $\approx 0.2 \mu \mathrm{m}$ below the surface. The SPER process at $723 \mathrm{~K}$ is also detectable by TEM (Fig. 3).

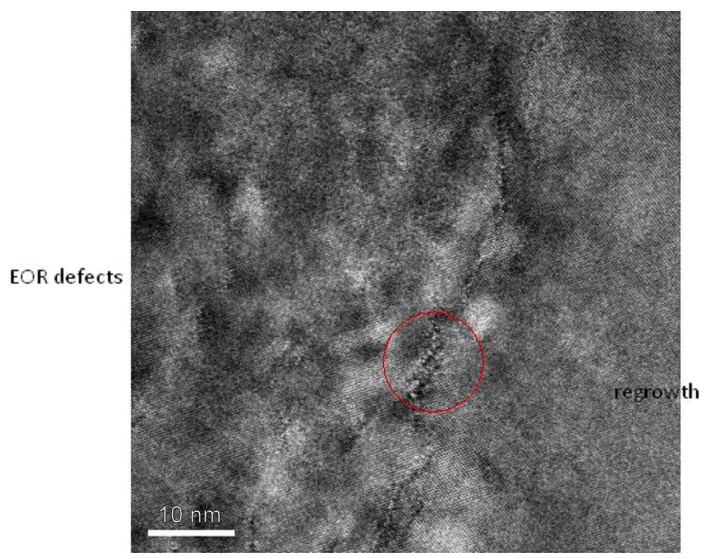

Fig. 3. Sectional TEM pattern of $\mathrm{Si}: \mathrm{V}(D=5 \times$ $10^{15} \mathrm{~cm}^{-2}$ ) processed for $10 \mathrm{~h}$ at $723 \mathrm{~K}$ under $1.1 \mathrm{GPa}$.

Vanadium atoms are piling up at the regrowth-a-Si area (the circle in the middle of TEM pattern). The top near-surface 70-80 nm thick area of Si:V indicates SPER, the so called end-of-range (EOR) defects are detectable below $R_{\mathrm{p}}$.

Depending on HP, the formation of the $\mathrm{VSi}_{2}$ phase and even more distinct SPER are detected after processing at $\mathrm{HT} \geq 900 \mathrm{~K}$. Usually the maximum $\mathrm{V}$ concentration has been detected below $R_{\mathrm{p}}$, at a depth of about $280 \mathrm{~nm}$, while the minimum concentration - just near $R_{\mathrm{p}}$ (Fig. 4).

As seen in the vanadium depth profiles, diffusivity of vanadium atoms toward the $\mathrm{Si}: \mathrm{V}$ surface is decreasing a little with HP in the case of processing at $1070 \mathrm{~K}$.

As detected by the synchrotron measurements (Fig. 5), no additional peaks were observed on $\mathrm{RC}$ in the case of Si:V processed at $1070 \mathrm{~K}$. This means that the layered structure, characteristic of the as-implanted samples, ceased to exist (compare Fig. 2) and so, in general, most of the near-surface material was subjected to SPER.

Still, as it is seen on the X-ray reciprocal space maps (XRRSMs, Fig. 6), the re-grown area remains to be far from being the perfect one in terms of the defects con- 


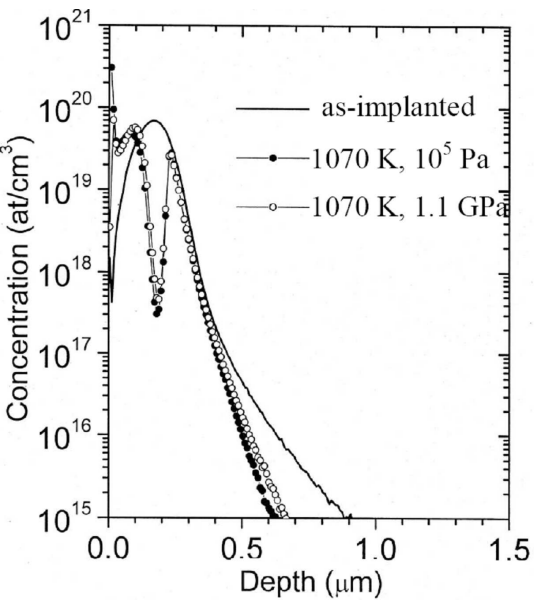

Fig. 4. Depth profiles of vanadium in $\mathrm{Cz}-\mathrm{Si}: \mathrm{V}(D=$ $1 \times 10^{15} \mathrm{~cm}^{-2}$ ), as implanted and processed at $1070 \mathrm{~K}$ under $10^{5} \mathrm{~Pa}$ and $1.1 \mathrm{GPa}$.
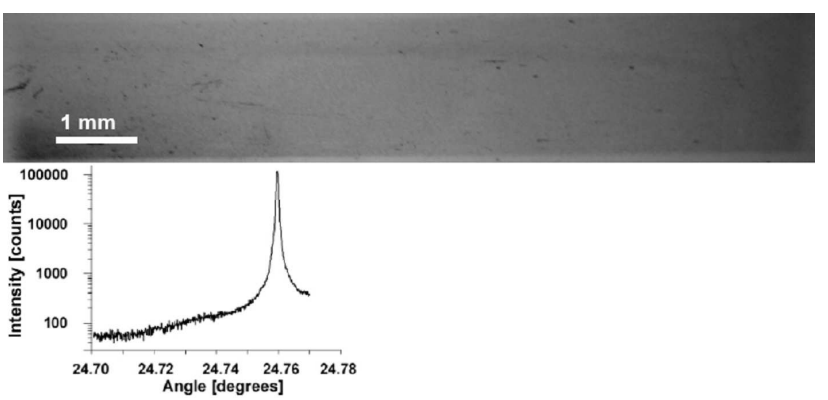

Fig. 5. Synchrotron monochromatic beam topograph $(\lambda=0.1115 \mathrm{~nm})$ and $004 \mathrm{RC}$ of $\mathrm{Si}: \mathrm{V}(D=1 \times$ $10^{15} \mathrm{~cm}^{-2}$ ) processed for $5 \mathrm{~h}$ at $1070 \mathrm{~K}$ under $1.1 \mathrm{GPa}$.

centration. Much narrower XRRSM pattern in the case of $\mathrm{Si}: \mathrm{V}$ treated under HP (Fig. 6B) evidences the HP-related improved sample perfection being still, however, much worse than that for the really perfect Si single crystal.

Processing of Si:V at $1400 \mathrm{~K}$ produces similar V depth profiles as that at $1070 \mathrm{~K}$ (compare Figs. 1 and 4) while

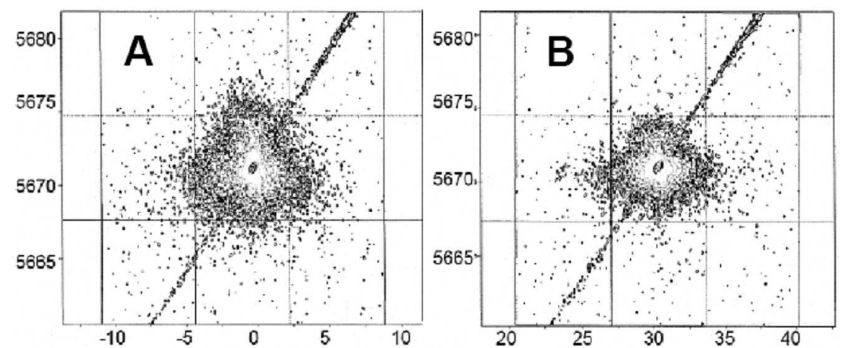

Fig. 6. XRRSMs of Cz-Si:V $\left(D=5 \times 10^{15} \mathrm{~cm}^{-2}\right)$, processed for $5 \mathrm{~h}$ at $1270 \mathrm{~K}$ under $10^{5} \mathrm{~Pa}(\mathrm{~A})$ and $1.12 \mathrm{GPa}(\mathrm{B})$. Axis is given in $\lambda / 2 d$ units $(\lambda$ - wavelength, $d$ - interplanar distance). more vanadium atoms are gettered at the $\mathrm{Si}: \mathrm{V}$ surface and the vanadium concentration reaches minimum at about $0.2 \mu \mathrm{m}$ depth. This can be interpreted as indication of the structure reaching closer to some near-equilibrium state in respect of the vanadium distribution in the case of processing at 1070-1400 K.



Fig. 7. Synchrotron monochromatic beam topograph $(\lambda=0.1115 \mathrm{~nm})$ and $004 \mathrm{RC}$ of $\mathrm{Si}: \mathrm{V}(D=5 \times$ $10^{15} \mathrm{~cm}^{-2}$ ) processed for $5 \mathrm{~h}$ at $1400 \mathrm{~K}$ under $1.1 \mathrm{GPa}$.

As seen in synchrotron topography and follows from the shape of rocking curve (RC) (lack of the additional maxima on RC, Fig. 7), Si:V treated at $1400 \mathrm{~K}$ under 1.1 GPa does not present the layered structure in respect of the presence of differently structurally ordered films. The distribution of vanadium is highly non-uniform after processing at $1400 \mathrm{~K}$ (Fig. 1). Dense array of precipitates is seen in synchrotron topographs at the near-surface areas of the Si:V samples processed at $1400 \mathrm{~K}$ (Fig. 7, top). Their presence can be interpreted as evidencing creation of the $\mathrm{VSi}_{2}$ precipitates $[7,8]$.

Depending on $\mathrm{HP}$, formation of the $\mathrm{VSi}_{2}$ phase and distinct SPER seems to occur at HT $\geq 900 \mathrm{~K}$. Usually the maximum $\mathrm{V}$ concentration has been detected below $R_{\mathrm{p}}$, at a depth of about $280 \mathrm{~nm}$.

However, no direct evidence for the creation of the $\mathrm{VSi}_{2}$ phase has been delivered by synchrotron $2 \theta$ scans done using the glancing incidence geometry. This means that $\mathrm{VSi}_{2}$ precipitates are very small, distinctly of below $50 \mathrm{~nm}$ dimension.

As follows also from our earlier work [3], the sharp minimum in the $\mathrm{V}$ concentration at $\approx 0.20 \mu \mathrm{m}$ below the surface exists in the Si:V samples processed at 870-1270 K. The vanadium distribution in the top $0.30 \mu \mathrm{m}$ thick layer remains rather insensitive with respect to processing temperatures and pressures within the 1070-1400 K range.

In the case of implantation at $E=200 \mathrm{keV}$ with $D=1 \times 10^{15} \mathrm{~cm}^{-2}$, the total energy introduced during implantation into silicon is above the amorphization threshold energy density for the implanted transition metal [8]. Therefore the a-Si layer is formed near the surface of single crystalline silicon (c-Si) up to the depth of about $0.25 \mu \mathrm{m}$.

At annealing, the a-Si layer is subjected to SPER. This results in the movement of the a-c interface toward the Si surface. Since the solubility of $\mathrm{V}$ in crystalline $\mathrm{Si}$ is very 
low, the $\mathrm{V}$ ions are expelled from the re-growth region, as the a-c interface moves toward the surface. Through this "snow-plow" process, a minimum in the $\mathrm{V}$ concentration profile was formed around $\approx 0.2 \mu \mathrm{m}$ below the surface.

The excess $\mathrm{V}$ ions are accumulated at the a-c interface, and eventually the $\mathrm{V}$ concentration reaches a point where this process can no longer push out the excess $\mathrm{V}$ impurity. At the temperatures in the $870-1400 \mathrm{~K}$ range, the a-Si layer is converted into a quasi-crystalline state and $\mathrm{VSi}_{2}$ is formed [7].

The enthalpy of $\mathrm{VSi}_{2}$ formation equals $3.2 \mathrm{eV}$ [9], so once formed $\mathrm{VSi}_{2}$ remains to be stable. Moreover, the outdiffusion of vanadium is almost negligible [10]. The similarity of the $\mathrm{V}$ distribution within the near-surface $0.30 \mu \mathrm{m}$ thick layer (Figs. 1 and 4 ) gives strong evidence that vanadium forms vanadium silicides. However, at a depth exceeding $0.4 \mu \mathrm{m}$, the tail end of the $\mathrm{V}$ distribution becomes distinctly narrower. This suggests that the concentration of $\mathrm{V}$ in this region is low enough so that $\mathrm{V}$ predominately exists in the form of individual atoms. The $\mathrm{VSi}_{2}$ nanoclusters formed around the $0.3 \mu \mathrm{m}$ depth, trap these excess $\mathrm{V}$ atoms and so attract vanadium from the 0.40 to $1.0 \mu \mathrm{m}$ depth at $1070-1270 \mathrm{~K}$.

The HT-HP treatment of $\mathrm{Si}: \mathrm{V}$ at lower temperatures does not affect markedly its microstructure, implying the presence of a layered structure composed of a-Si film on the nearly perfect $\mathrm{Si}$ substrate.

This layered structure ceases to exist after processing at $T>1070 \mathrm{~K}$.

As follows from XRRSMs, processing of Si:V at 1070 $1270 \mathrm{~K}$ results in SPER of the a-Si layer. No marked structural differences between the re-grown region at $<0.3 \mu \mathrm{m}$ depth and the single crystalline silicon substrate were detected after $\mathrm{Si}: \mathrm{V}$ processing at 1270 $1400 \mathrm{~K}$.

It is worth mentioning that contrary to the diffusion behaviour of $\mathrm{V}$ in Si:V, SIMS measurements of Si:Cr, implanted with $\mathrm{Cr}^{+}$at $D=1 \times 10^{15} \mathrm{~cm}^{-2}$, indicate that the $\mathrm{a}-\mathrm{c}$ interface shift during processing is distinctly affected by HP [4].

\section{Conclusions}

The structure of $\mathrm{Cz}-\mathrm{Si}: \mathrm{V}$ is strongly dependent on the implantation and processing conditions, hydrostatic pressure among them. Enhanced hydrostatic pressure ap- plied at processing of $\mathrm{Si}: \mathrm{V}$ results in the improved crystallographic perfection. This seems to be caused, among others, by the effect of $\mathrm{HP}$ on diffusivity of $\mathrm{V}^{+}$and of implantation-induced point defects.

We hope that our research will assist in solving still existing controversies concerning mechanisms of the creation of specific crystalline magnetically ordered phases and of quasi-ferromagnetism in the ion implanted Si-based materials. Further research will attribute to understanding the basics of ferromagnetic ordering in $\mathrm{Si}: \mathrm{V}$ and in similar systems.

\section{References}

[1] A. Misiuk, J. Bak-Misiuk, B. Surma, W. Osinniy, M. Szot, T. Story, J. Jagielski, J. Alloys Comp. 423 , 201 (2006).

[2] A. Wolska, K. Lawniczak-Jablonska, M. Klepka, M.S. Walczak, A. Misiuk, Phys. Rev. B 75, 113201 (2007).

[3] A. Misiuk, L. Chow, A. Barcz, B. Surma, J. Bak-Misiuk, P. Romanowski, W. Osinniy, F. Salman, G. Chai, M. Prujszczyk, A. Trojan, in: High Purity Silicon 9, Eds. C.L. Claeys, R. Falster, M. Watanabe, P. Stallhofer, Electrochemical Society, Inc., Pennington (NJ) 2006, p. 481.

[4] A. Misiuk, A. Barcz, L. Chow, B. Surma, J. Bak-Misiuk, M. Prujszczyk, Solid State Phenom. 131-133, 375 (2008).

[5] A. Misiuk, A. Barcz, L. Chow, Phys. Tekhn. Vys. Davlenii 18, 105 (2008).

[6] T. Figielski, in: Proc. V Int. Summer School on Defects, Krynica (Poland) 1976, Eds. T. Figielski, M. Jastrzebska, W. Szkiełko, , Polish Sci. Publishers, Warszawa 1978, p. 237.

[7] S.P. Murarka, Silicides for VLSI Applications, Academic Press, New York 1983.

[8] K.S. Jones, S. Prussin, E.R. Weber, Appl. Phys. A, Solid Surf. 45, 1 (1988).

[9] J.M. Andrews, J.C. Phillips, Phys. Rev. Lett. 35, 56 (1975).

[10] P. Zhang, F. Stevie, R. Vanfleet, R. Neelakantan, M. Klimov, D. Zhou, L. Chow, J. Appl. Phys. 96, 1053 (2004). 